\title{
ВсемирнАя история
}

\section{Усеагульна п псторыя}

\section{WorlD Histoory}

УДК 364(44)(091)«2017/2021»

\section{ФРАНЦУЗСКАЯ СОЦИААИСТИЧЕСКАЯ ПАРТИЯ В 2017-2021 гГ.: АААПТАЦИЯ К НОВОЙ СИТУАЦИИ}

\author{
Е. Г. КОЛБ ${ }^{1)}$
}

1) Белорусский государственный университет, пр. Независимости, 4, 220030, г. Минск, Беларусь

Впервые в белорусской исследовательской литературе рассматривается деятельность Французской социалистической партии (ФСП) по преодолению тяжелейшего идейно-политического кризиса, отчетливо проявившегося на выборах 2017 г. Показаны результаты внутрипартийной борьбы по вопросу стратегии восстановления позиций в политической жизни страны. Охарактеризованы изменения в идеологии и определена степень обновления партийной доктрины, установлены особенности деятельности ФСП в роли оппозиционной партии, показаны усилия социалистов по сплочению левых сил, установлена специфика роли ФСП в политической жизни и левом лагере Франции. Делается вывод о том, что ФСП отказалась от радикального пересмотра идеологии и политической стратегии и сохранила идейно-политическую идентичность левой правительственной партии, сумела избежать превращения в микропартию, но так и не смогла восстановить прежнюю роль доминирующей силы левого лагеря и одной из двух ведущих партий страны.

Ключевые слова: Французская социалистическая партия; идеология; политическая стратегия; выборы.

Образец цитирования:

Колб ЕГ. Французская социалистическая партия в 20172021 гг.: адаптация к новой ситуации. Журнал Белорусского государственного университета. История. 2022; $1: 43-50$. https://doi.org/10.33581/2520-6338-2022-1-43-50

\section{For citation:}

Kolb EG. The French Socialist Party in 2017-2021: adaptation to the new situation. Journal of the Belarusian State University. History. 2022;1:43-50. Russian.

https://doi.org/10.33581/2520-6338-2022-1-43-50

\section{Ав тор:}

Евгений Георгиевич Колб - кандидат исторических наук, доцент; доцент кафедры истории нового и новейшего времени исторического факультета.

\section{Author:}

Eugene G. Kolb, PhD (history), docent; associate professor at the department of modern and contemporary history, faculty of history.

eg.kolb.64@gmail.com 


\title{
ФРАНЦУЗСКАЯ САЦЫЯАІСТЫЧНАЯ ПАРТЫЯ Ў 2017-2021 гГ.: АААПТАЦЫЯ АА НОВАЙ СІТУАЦЫІ
}

\author{
Я. г. коль ${ }^{1^{*}}$ \\ 1* Беларускі дзяржаўны ўніверсітэт, пр. Незалежнасці, 4, 220030, г. Мінск, Беларусь
}

\begin{abstract}
Упершыню ў беларускай даследчыцкай літаратуры разглядаецца дзейнасць Французскай сацыялістычнай партыі (ФСП) па пераадоленні самага цяжкага ідэйна-палітычнага крызісу, які яскрава праявіўся на выбарах 2017 г. Паказаны вынікі ўнутрыпартыйнай барацьбы па пытанні стратэгіі аднаўлення пазіцый партыі ў палітычным жыцці краіны. Ахарактарызаваны змены ў ідэалогіі і вызначана ступень абнаўлення партыйнай дактрыны, высветлены асаблівасці дзейнасці ФСП у якасці апазіцыйнай партыі, паказаны намаганні сацыялістаў па згуртаванні левых сіл, вызначана спецыфіка ролі ФСП у палітычным жыцці і левым лагеры Францыі. Зроблена выснова аб тым, што ФСП адмовілася ад кардынальнага перагляду ідэалогіі і палітычнай стратэгіі, здолела пазбегнуць параўтварэння ў мікрапартыю, але не аднавіла былую ролю дамінуючай сілы левага лагера і адной з дзвюх галоўных партый краіны.
\end{abstract}

Ключавыя словы: Французская сацыялістычная партыя; ідэалогія; палітычная стратэгія; выбары.

\section{THE FRENCH SOCIALIST PARTY IN 2017-2021: ADAPTATION TO THE NEW SITUATION}

\author{
E. G. KOLB ${ }^{\mathrm{a}}$ \\ ${ }^{\mathrm{a}}$ Belarusian State University, 4 Niezaliežnasci Avenue, Minsk 220030, Belarus
}

For the first time in the Belarusian research literature, the activities of the French Socialist Party (FSP) to overcome the most severe ideological and political crisis that clearly manifested itself in the 2017 elections is examined. The author shows the results of the internal party struggle on the strategy of restoring the party's position in the political life of the country. In the article the changes in the ideology are characterised and the degree of renewal of the party doctrine is determined, the features of the activity of the FSP in the role of the opposition party are established, the efforts of socialists to rally the left forces are shown, the specifics of the role of the FSP in political life and the left political camp of France are established. It is concluded that the FSP refused a deep revision of ideology and political strategy and kept the ideological and political identity of the left government party, its authorities managed to avoid transformation to a micro-party, but they were unable to restore the former role of the main party of the left political camp and one of the two leading parties in the country.

Keywords: French Socialist Party; ideology; political strategy; elections.

После президентских выборов 2017 г. Французская социалистическая партия (ФСП) оказалась в ситуации, близкой к катастрофической. Она не только потерпела самое тяжелое за годы Пятой республики поражение, но и утратила статус одной из двух ведущих партий страны, который имела на протяжении четырех предыдущих десятилетий. Одновременно ФСП потеряла доминирование в левом лагере, которое сохраняла с 1981 г. при всех электоральных неудачах. На ведущую роль в левом лагере стала вполне реально претендовать левопопулистская партия «Непокоренная Франция». Кроме того, левые партии начали избегать сотрудничества с ФСП, ставшей «токсичной» из-за политики президентасоциалиста Ф. Олланда. Развернувшаяся в партии после 2012 г. острая борьба левого и правого крыла по вопросам идеологии и стратегии создала впечат- ление о расколе в ФСП, которое усилилось в связи с выходом из партии ряда ведущих политиков во время выборов 2017 г. и сразу после них. Еще одной проблемой стало отсутствие у социалистов «естественного» лидера, популярного среди сторонников партии, способного убедить партийную массу в правильности предлагаемой им стратегии. Более того, после отставки в сентябре 2016 г. Ж.-К. Камбаделиса ФСП лишилась даже формального главы и управлялась коллективным руководством. Неудивительно, что в ноябре 2017 г. 74 \% французов, в том числе $63 \%$ сторонников левых сил и 48 \% сторонников ФСП, считали возможным исчезновение партии с политической арены страны ${ }^{1}$.

За последние четыре десятилетия ФСП показала способность быстро оправляться от поражений, даже самых тяжелых. Но после 2017 г. социалистам

\footnotetext{
${ }^{1}$ Pour les Français, le PS est «un grand cadavre à la renverse» [Ressource électronique]. URL: https://www.odoxa.fr/sondage/ francais-ps-grand-cadavre-a-renverse/ (date de la demande: 05.12.2017).
} 
приходилось восстанавливать позиции в новой политической ситуации, созданной кризисом системных партий, назревавшим с 1980-х гг. и проявившимся в полную силу на выборах 2017 г. Наблюдавшееся в обществе усиление популистских настроений напрямую затрагивало ФСП, которая отождествлялась населением с управленческой элитой. Кроме того, центральной осью политической жизни вместо традиционного противостояния левых и правых сил стало противоборство прогрессистского и суверенистско-популистского лагерей. Все это затрудняло использование партией привычных методов восстановления политических позиций.

Деятельность ФСП после выборов 2017 г. не получила широкого освещения в исследовательской литературе. В работах российских исследователей А. А. Вершинина [1] и Е. А. Нарочницкой [2] отражены трудности, возникшие у партии социалистов после выборов, и выделены основные задачи, которые необходимо было решить ФСП. Но действия по решению появившихся проблем не получили к настоящему времени освещения в русскоязычной литературе. Французскими политологами прокомментированы в СМИ отдельные события в жизни партии и действия ее руководства. Но развернутые исследования деятельности ФСП в период легислатуры Э. Макрона появятся во французской научной литературе скорее всего уже после выборов 2022 г. Настоящая статья, не претендующая на полноту раскрытия вопроса, является первой в отечественной науке попыткой проанализировать действия социалистов по адаптации к новой политической ситуации. Цель работы заключается в выделении особенностей стратегии руководства ФСП по усилению ее позиций и выявлении эффекта от предпринятых партией усилий.

После выборов 2017 г. среди социалистов наблюдался подъем обновленческих настроений, который с 1986 г. всякий раз сопровождал поражение ФСП на общенациональных выборах. Звучали ставшие привычными предложения обновить идеологию и внутреннюю жизнь партии, методы ее политической деятельности и стратегию альянсов. Также члены ФСП выражали надежду, что съезд 2018 г. станет повторением съезда 1971 г. в Эпине, положившего начало превращению ФСП в одну из главных партий страны.

При подготовке к съезду 2018 г. четыре претендента на пост главы ФСП предложили свои проекты переустройства партии. Во всех из них отмечалась необходимость обновления партийной доктрины с учетом новейших изменений в обществе и уроков, вынесенных во время правления Ф. Олланда. Все претенденты считали, что идеология ФСП должна базироваться на традиционных ценностях французского социализма, а партийный проект развития общества должен быть альтернативой неолиберальному курсу. Также они предлагали одинаковый путь обновления партийной доктрины - внедрение в нее экологических ценностей.

В то же время внутри партии наблюдались разногласия по вопросу о проявлении ее левой идентичности. Так, в проекте одного из лидеров левого крыла Э. Мореля ставилась задача «вновь подтвердить необходимость социалистического пути, отличного от социал-либерализма» ${ }^{2}$ (здесь и далее перевод наш. - E. К.). Фактически это был призыв отступить от утвердившейся с 1983 г. тенденции ориентироваться на учет объективных реалий в предложениях социалистов и в их действиях при нахождении у власти. Такая стратегия позволила ФСП обрести имидж ответственной партии и возможность успешно бороться за власть. В то же время переход к культуре управления вызвал умеренность предложений социалистов, а также обусловил проведение ими прагматичной политики, которая воспринималась частью левого электората как социал-либеральный курс и вызывала кризисы идентичности ФСП всякий раз при нахождении социалистов у власти.

Сходная позиция содержалась в проекте Л. Карвунаса, где отмечалась необходимость «порвать с почти сорокалетним понятием правительственной партии» ${ }^{3}$. С. Ле Фолль, один из ближайших соратников Ф. Олланда, был против возврата социалистов к культуре оппозиции с характерным для нее выдвижением привлекательных, невыполнимых обещаний. В его проекте констатировалась недопустимость предложений, «которые обеспечат нам комфортное место в роли оппозиции без возможности их реализовать, когда мы будем у власти» 4 В проекте О. Фора, главы фракции социалистов в Национальном собрании, содержался усредненный подход. В нем отмечалось, что ФСП должна стать воплощением «одновременно правительственной левой [партии] и левой [партии] социальной трансформации» 5 .

Относительно политической стратегии все претенденты считали, что ФСП должна находиться в оппозиции к президенту Э. Макрону, развивать диалог с гражданским обществом и сотрудничать с партиями левого лагеря. Тем не менее в предлагаемых

\footnotetext{
${ }^{2}$ Texte d'orientation d'Emmanuel Maurel. L’union et l'espoir [Ressource électronique]. URL: https://www.partisocialiste92.fr/ storage/2020/07/TO-4.pdf (date de la demande: 19.07.2021).

${ }^{3}$ Texte d'orientation de Luc Carvounas. Un progrès partagé pour faire gagner la gauche [Ressource électronique]. URL: https:// www.partisocialiste92.fr/storage/2020/07/TO-1.pdf (date de la demande: 19.07.2021).

${ }^{4}$ Texte d'orientation de Stéphane Le Fol. Cher.E.S camarades [Ressource électronique]. URL: https://www.partisocialiste92.fr/ storage/2020/07/TO-2.pdf (date de la demande: 19.07.2021).

${ }_{5}^{5}$ Texte d'orientation d'Olivier Faur. Socialistes, le chemin de la Renaissance [Ressource électronique]. URL: https://partisocia liste92.fr/storage/2020/07/TO-3.pdf (date de la demande: 19.07.2021).
} 
проектах имелись различия по вопросу о формате сотрудничества с левыми партиями. Главные расхождения наблюдались в вопросах об отношении к левым популистам и о роли ФСП в левой коалиции. Так, Э. Морель высказался за политический союз левых партий всех идейных оттенков на основе общей программы без доминирования ФСП. В проекте Л. Карвунаса содержалась схожая идея широкой левой коалиции, но отвергалось электоральное сотрудничество с левыми популистами. В резолюции С. Ле Фолля предлагалось создать федерацию левых партий без участия популистов с ведущей ролью ФСП. В проекте О. Фора ничего не говорилось о формате взаимодействия левых сил и отмечалось, что «поднимать сегодня вопрос об альянсах означало бы поставить себя в положение слабого, сначала надо возродить силу ФСП» 6 .

При голосовании членов партии проект О. Фора заметно опередил остальные варианты развития ФСП, получив 48,5 \% голосов. После столь убедительного успеха О. Фор в марте 2018 г. был избран новым главой партии социалистов (86 \% голосов), и в апреле 2018 г. на партийном съезде его официально утвердили на этом посту. Показательно, что недавние конкуренты не стали использовать трибуну съезда для демонстрации расхождений взглядов с новым главой ФСП.

Несмотря на проявленное на съезде фасадное единство, многие наблюдатели отмечали, что О. Фору предстоит решить сложную задачу по сплочению партийных рядов, особенно в части налаживания бесконфликтного сотрудничества с левым крылом ФСП. Решение этой задачи облегчил выход из партии в октябре 2018 г. лидеров левого крыла Э. Мореля и Н.-М. Лиенманн из-за несогласия с линией руководства. Расчет Э. Мореля на то, что этот демарш поддержат «сотни [партийных] кадров, депутатов местных органов и мэров» ${ }^{7}$, не оправдался, а уход признанных лидеров ощутимо снизил активность левого крыла. В результате внутрипартийное противостояние стало практически незаметным. Тем самым О. Фор выполнил озвученное после избрания главой ФСП обещание покончить с делением партии на противоборствующие группировки ${ }^{8}$.

Одним из направлений работы руководства ФСП по усилению позиций партии стала борьба против политики действующей власти. Развернутая социалистами критика политики президента строилась вокруг темы «Макрон - президент богачей». Ее ин- струментами стали настенные плакаты, видеоролики в социальных сетях, статьи в прессе. Критика намерений власти велась и парламентариями ФСП при обсуждении правительственных законопроектов. Кроме того, фракциями ФСП было выдвинуто 17 законопроектов, посредством которых партия демонстрировала свою левую идентичность и наличие альтернативных планов развития страны.

При этом социалисты, поддерживая имидж ответственной партии, отказались от фронтального противостояния с действующей властью. ФСП, в отличие от партии «Непокоренная Франция», не пыталась инициировать выступления против правительственной политики. Во время массовых протестов 2018-2020 гг. партия призывала руководство страны прислушаться к выдвигаемым требованиям и предлагала пути решения вызвавших разногласия проблем. Оппозиционный дискурс ФСП и ее контрпредложения были менее радикальными, чем у популистских партий.

Такая тактика стала одной из причин того, что ФСП не воспринималась населением как главная оппозиционная сила страны. По этому показателю она на протяжении 2018-2020 гг. неизменно уступала популистским партиям «Непокоренная Франция» и «Национальное объединение» (ранее - «Национальный фронт»), а также правой партии «Республиканцы». Тем не менее ФСП последовательно воздерживалась от призывов и предложений с популистским оттенком. В этом плане социалисты следовали установке, озвученной О. Фором осенью 2018 г.: «...мы никогда не будем популистами... Популизм - это в первую очередь способ обманывать народ. Мы этого никогда не делали» ${ }^{9}$.

Еще одним магистральным направлением усилий руководства ФСП по укреплению позиций партии было развитие сотрудничества партий левого лагеря. С 2018 г. О. Фор постоянно выступал за создание альянса левых партий, утверждая, что, только сплотившись, левый лагерь получит шансы добиться электоральных успехов. Лидер социалистов отнюдь не сгущал краски, поскольку за 2017-2020 гг. среди населения Франции доля лиц, придерживающихся левых взглядов, снизилась с 15 до 13 \%, доля центристов - с 38 до 32 \%, тогда как доля лиц, придерживающихся правых взглядов, увеличилась с 36 до $39 \%{ }^{10}$. При этом сторонники правых взглядов преобладали среди категорий граждан, традиционно воспринимаемых как «естественная» социальная база левых

\footnotetext{
${ }^{6}$ Texte d'orientation d'Olivier Faur. Socialistes, le chemin de la Renaissance [Ressource électronique]. URL: https://partisocia liste92.fr/storage/2020/07/TO-3.pdf (date de la demande: 19.07.2021).

${ }^{7}$ Le leader de l'aile gauche du PS Emmanuel Maurel quitte le parti [Ressource électronique]. URL: https://www.lejdd.fr/Politique/ le-leader-de-laile-gauche-du-ps-emmanuel-maurel-quitte-le-parti-3776885 (date de la demande: 25.10.2018).

${ }^{8} \mathrm{Au}$ congrès du PS, Olivier Faure veut ouvrir une nouvelle page [Ressource électronique]. URL: https://www.lemonde.fr/ politique/article/2018/04/08/au-congres-du-ps-olivier-faure-veut-couvrir-une-nouvelle-page_5282484_823448.html (date de la demande: 10.04.2018).

${ }^{9}$ Olivier Faure réagit aux départs du PS : «Nous ne serons jamais populists» [Ressource électronique]. URL: https://www.lejdd.fr/ Politique/olivier-faure-reagit-au-depart-du-ps-nous-ne-seront-jamais-populistes-3777962 (date de la demande: 15.10.2018).

${ }^{10}$ Le positionnement des Français sur un axe gauche-droite [Ressource électronique]. URL: https://www.ifop.com/publication/ le-positionnement-des-Francais-sur-un-axe-gauche-droite-2/ (date de la demande: 25.07.2020).
} 
сил: молодежи, служащих, рабочих, работников государственного сектора. Тем не менее левый лагерь в случае объединения усилий сохранял значительный политический потенциал. Так, в апреле 2021 г. по числу сторонников левые партии в совокупности (25 \%) опережали традиционные правые организации (10\%), Национальное объединение (14\%) и партии президентского большинства $(13 \%)^{11}$.

Создание союза левых сил со времен съезда 1971 г. являлось одним из главных принципов стратегии ФСП. Но после 1981 г. социалисты считали, что такой союз должен образоваться под эгидой ФСП как наиболее сильной партии левого лагеря. Теперь же О. Фор предлагал союз равноправных партнеров, который будет базироваться на общей программе с выдвижением на выборах единых кандидатов или списков. Фактически это был план создания левой коалиции по образцу существовавшего в 1970-х гг. союза левых сил.

Стремясь облегчить создание такой коалиции, руководство ФСП на деле показало готовность поступиться интересами партии ради сплочения левых. На выборах 2019 г. в Европарламент социалисты уступили первенство в предвыборном списке Р. Глюксману, главе микропартии «Общественное место», вошедшей в созданный вокруг ФСП электоральный альянс. На муниципальных выборах 2020 г. ФСП, вопреки устоявшемуся правилу, отдала в ряде крупных городов руководство объединенными списками левых сил представителям партии «Европа - Экология - Зеленые» (Europe Ecologie les Verts; далее - ЕЕЛВ). В августе 2020 г. О. Фор сделал еще более решительный шаг, предложив выдвинуть на президентских выборах 2022 г. единого кандидата левых сил, которого социалисты поддержат, даже если он не будет членом ФСП ${ }^{12}$.

Сначала призывы лидера социалистов к сплочению левого лагеря не получили поддержки. К выборам 2019 г. ФСП удалось заключить электоральный союз только с тремя левыми микропартиями. Более крупные организации предпочли действовать самостоятельно, намереваясь использовать эти выборы, традиционно воспринимаемые как малозначимые, для проверки своего политическо- го веса. Выступление социалистов (6,2 \% голосов) было расценено наблюдателями как продолжение политического падения партии. Некоторым утешением являлся тот факт, что партия «Непокоренная Франция» показала примерно равный с ФСП результат (6,3 \%), но тревожным знаком стало появление нового претендента на роль лидера левого лагеря в лице ЕЕЛВ (13,5 \%).

С приближением муниципальных выборов 2020 г. О. Фор вновь призвал к созданию электорального союза левых сил. На этот раз левые партии, заботясь о представительстве в местных органах власти, пошли на создание в ряде городов и коммун единых списков с участием ФСП. Оценивая выступление левого лагеря на этих выборах, наблюдатели уделили первоочередное внимание результатам ЕЕЛВ, трактуя их как новый успех партии в борьбе за лидерство в левом лагере. Но выборы стали также успехом для ФСП, добившейся наилучших результатов среди левых партий. Социалисты возглавили 6 городов с населением более 200 тыс. человек (ЕЕЛВ - 3), 14 городов с населением свыше 100 тыс. человек (ЕЕЛВ - 6), а также 47 коммун с населением более 30 тыс. жителей (ЕЕЛВ - 9, коммунистическая партия -15$)^{13}$. Еще более отчетливым успехом ФСП стали региональные выборы 2021 г. На них левые силы вновь использовали тактику электоральных союзов, но единые списки с первого тура выдвинули только в двух регионах. На выборах социалисты завоевали руководство в 5 из 13 регионов в метрополии, тогда как ЕЕЛВ и партия «Непокоренная Франция» не сумели возглавить ни одного.

Тем самым ФСП наряду с партией «Республиканцы» сохранила статус одной из двух доминирующих на местном уровне политических сил. Правда, успехи на выборах 2020-2021 гг. объяснялись не повышением авторитета ФСП, а удачной конъюнктурой. Предвыборные опросы показали, что французы в своем большинстве были удовлетворены работой действовавших администраций и не стремились к их замене ${ }^{14}$. В итоге на этих выборах, характеризующихся рекордным уровнем абсентеизма, большинство избирателей проголосовали за сохранение прежнего руководства ${ }^{15}$.

\footnotetext{
${ }^{11}$ La gauche est en crise, mais, unie elle disposerait d'un fort potential [Ressource électronique]. URL: http://www.odoxa.fr/son dage/gauche-crise-unie-disposerait-dun-fort-potentiel/ (date de la demande: 16.04.2021).

${ }^{12}$ Le PS pour le «rassemblement» avec les écolos mais l'union est «compliquée» [Ressource électronique]. URL: https://www. lepoint.fr/politique/le-ps-pour-le-rassenblement-avec-les-ecolos-mais-1-union-est-compliquee-29-08-2020-2389521_20.php (date de la demande: 31.08.2020).

${ }^{13}$ Rapport d'activité. D’aubervilliers à villeurbanne, de la renaissance à l'espérance [Ressource électronique]. URL: https:// d3n8a8pro7vhmx.cloudfront.net/laruchesocialiste/pages/3964/attachments/original/1628156842/VILL21_Rapportd'activit\% C3\%A9_V3.pdf?1628156842 (date de la demande: 12.08.2021).

${ }^{14}$ Municipales : sept Français sur dix satisfaits de leur maire [Ressource électronique]. URL: https://www.lefigaro.fr/flash-actu/ municipales-sept-francais-sur-dix-satisfaits-de-leur-maire-20200213 (date de la demande: 15.02.2020) ; Le baromètre politique Viavoice - Libération: «Le mystère des municipales». Mars 2020 [Ressource électronique]. URL: https.://www.institut-viavoice.com/ wp-content/uploads/2020/03/Baromètre-politique-Viavoice-Libération.-Mars-2020.pdf (date de la demande: 15.03.2020).

${ }^{15}$ Municipales 2020 : comprendre le vote des Français [Ressource électronique]. URL: https://www.ipsos.com/fr-fr/munici pales-2020-comprendre-le-vote-des-francais (date de la demande: 12.05.2020) ; Les enjeux du vote aux élections régionales et la place des questions de sécurité dans le choix des Français [Ressource électronique]. URL: https://www.ifop.com/publication/lesenjeux-du-vote-aux-elections-regionales-et-la-place-des-questions-de-securite-dans-le-choix-des-francais/ (date de la demande: 19.06.2021).
} 
Но это обстоятельство не помешало О. Фору летом 2021 г. заговорить о том, что ФСП является движущей силой левого лагеря и именно под ее руководством он имеет наибольшие шансы на успех на грядущих общенациональных выборах ${ }^{16}$. Однако призывы О. Фора выдвинуть единого кандидата в президенты не получили поддержки среди представителей других левых партий, сделавших выбор в пользу самостоятельного выступления. Это можно считать главной неудачей стратегии лидера социалистов по сплочению левых сил.

Более того, эта стратегия вызвала обеспокоенность в рядах социалистов. В 2019-2020 гг. прозвучали заявления ряда политиков ФСП о том, что действия первого секретаря угрожают «стиранием» партии с политического ландшафта страны. Эта критика в сочетании с отсутствием прогресса в создании левой коалиции вынудила партийное руководство активизировать подготовку ФСП к общенациональным выборам 2022 г. В феврале 2021 г. началась разработка предвыборной программы социалистов, а в проекте развития ФСП, выдвинутом О. Фором к съезду 2021 г., был определен порядок избрания партийного кандидата в президенты и оказана поддержка кандидатуре А. Идальго ${ }^{17}$.

Этих действий оказалось недостаточно, чтобы успокоить волнение, возникшее в партийных рядах, и при подготовке к съезду 2021 г. у О. Фора появился соперник в борьбе за пост главы партии в лице Э. Жоффруа. В ее проекте развития критиковалось действующее руководство ФСП за нехватку внутрипартийной демократии, запаздывание с разработкой программы к выборам 2022 г. и стратегию альянсов, не имевшую успеха и ведущую к «стиранию» партии ${ }^{18}$. Но, хотя проект Э. Жоффруа позиционировался как альтернатива стратегии правительственной партии, в нем не просматривались существенные расхождения с предложениями О. Фора в части действий социалистов при решении проблем страны. В этой плоскости главным отличием стало, пожалуй, признание возможности увеличить государственный долг во имя «разумных и эффективных расходов, являющихся подлинным инвестированием в людей и наши общественные службы» ${ }^{19}$. Еще одно отличие в проектах наблюдалось в вопросе о формате сотрудничества левых сил. Если О. Фор вновь высказался за создание коалиции равноправных партнеров на основе общей программы, то Э. Жоффруа выступила за объединение левых сил под эгидой ФСП.

На голосовании членов партии проект ее лидера (76,18 \% голосов) уверенно опередил проект его соперницы (23,82 \% голосов), а О. Фор был переизбран главой ФСП, получив 73,49 \% голосов (Э. Жоффруа получила 26,51 \% голосов). В сентябре 2021 г. партийный съезд официально утвердил О. Фора на посту первого секретаря.

Также на съезде была одобрена программа ФСП к выборам 2022 г., позволяющая оценить изменения в идейно-политическом позиционировании партии $^{20}$. Главной новацией стала интеграция в партийную доктрину экологических ценностей. Это выразилось в том, что экологические императивы наряду с социальными фигурировали в изложении намерений социалистов по переустройству общества. Если ранее в программах ФСП экология присутствовала лишь как одно, отнюдь не приоритетное, направление политики, то теперь она стала составной частью партийной трактовки сущности социального прогресса. В остальном же система ценностей и принципов партии не претерпела изменений. В программе был даже специальный раздел, в котором обосновывалась верность ФСП идеалам французского социализма ${ }^{21}$.

Логической доминантой программы партии являлась установка на трансформацию общества путем решительной политики, исторически отражавшая идейное своеобразие французского социалистического движения. Стремление к глубокому преобразованию общества выразилось в просматриваемом документе в виде двух глобальных проектов. Первым стал проект экологического перехода, призванный установить новую модель развития социума. Главным принципом этой модели партия назвала «примат жизни над экономикой» ${ }^{22}$, отступив тем самым от утвердившейся с 1983 г. в программных документах ФСП установки на строгий учет экономических реалий. Вторым направлением трансформации общества была названа всеобъемлющая реализация фундаментальных принципов Французской республики с распространением их действия на все категории населения. Осуществле-

\footnotetext{
${ }^{16}$ Régionales: pour Faure, les Verts n'ont «pas atteint la crédibilité nécessaire pour concourir» à une victoire [Ressource électronique]. URL: https://www.lefigaro.fr/elections/regionales/regionales-pour-faure-les-verts-n-ont-pas-atteint-la-credibilitenecessaire-pour-concourir-a-une-victoire-20210628 (date de la demande: 30.06.2021).

${ }^{17}$ Texte B. De la Renaissance à l'alternance. Olivier Faure [Ressource électronique]. URL: https://www.parti-socialiste.fr/tob_ delarenaissance (date de la demande: 19.07.2021).

${ }^{18}$ Texte A. Debout les Socialistes. Pour le renouveau! Hélène Geoffroy [Ressource électronique]. 24 p. URL: https://d3n 8a8pro7vhmx.cloudfront.net/laruchesocialiste/pages/3292/attachments/original/1625731312/TO_A_HG.pdf?1625731312 (date de la demande: 19.07.2021).

${ }^{19}$ Idem. P. 5.

${ }^{20}$ Le projet : «Il est temps de vivre mieux» [Ressource électronique]. 98 p. URL: https://d3n8a8pro7vhmx.cloudfront.net/laruche socialiste/pages/5980/attachments/original/1634117820/LEPROJET_V9.pdf?1634117820 (date de la demande: 08.09.2021).

${ }^{21}$ Idem. P. $18-22$.

${ }^{22}$ Idem. P. 23.
} 
ние такой политики трактовалось как способ переустройства общества на принципах социальной справедливости и равенства, как средство преодоления общественных противоречий и сплочения нации, а также как альтернатива неолиберальной социальной модели ${ }^{23}$. Социалисты ясно высказались за усиление госрегулирования, мотивируя его необходимость нарастанием социальных проблем и ухудшением экологической ситуации ${ }^{24}$. Предложения по усилению регулирования коррелировали со сформулированными ФСП в 1990-х гг. функциями государства-стратега, которое определяет главные ориентиры развития и содействует движению в этих направлениях, и государства-защитника, ограждающего общество от негативных последствий рыночной экономики и неолиберальной глобализации.

В то же время в содержании 111 предложений, выдвинутых в программе, не просматривалось стремление вернуться к культуре оппозиции. Таким образом ФСП сохранила выстроенную еще в 1980-х гг. политическую идентичность правительственной левой партии, верной своему идейному наследию, но учитывающей реалии современного общества в своих предложениях и действиях. Одобрение съездом предвыборной программы свидетельствует о том, что такая идентичность поддерживается большинством членов партии.

Итоги съезда 2021 г. стали бесспорным успехом О. Фора, чья деятельность на посту главы ФСП получила широкую поддержку в партийных рядах. Однако рано говорить о том, что он стал «естественным» лидером социалистов и одним из главных политиков левого лагеря. В 2019-2020 гг. он не входил в первую десятку списка политических деятелей, ассоциирующихся с будущим левого лагеря как у французов в целом, так и у сторонников левых сил в частности. О. Фор уступал представителям партии «Непокоренная Франция» и ЕЕЛВ, а среди политиков ФСП его опережали лидеры прошлых лет, а также А. Идальго, которая в 2020 г. в этом списке занимала 2-е место (первенство принадлежало Ж.-Л. Меланшону) ${ }^{25}$. Также лидер ФСП не считался сильным кандидатом в президенты как сторонниками левого лагеря, так и приверженцами собственной партии.

Заслугой О. Фора можно считать то, что под его руководством ФСП сумела избежать политической изоляции и превращения в микропартию. Вместе с тем социалистам не удалось заметно усилить позиции на национальном уровне и в левом лагере. Об этом свидетельствует прежде всего тот факт, что во всех опросах, касающихся президентских выборов, А. Идальго, избранная в октябре 2021 г. кандидатом ФСП, не имеет шансов на выход во второй тур, а также уступает Ж.-Л. Меланшону и кандидату ЕЕЛВ Я. Жадо.

Кроме того, опубликованный в сентябре 2021 г. опрос агентства Ipsos показал, что, по общественному мнению, ФСП не имеет явных преимуществ в сравнении с другими главными партиями ${ }^{26}$. Социалисты продолжают сохранять в глазах французов солидный управленческий имидж. По такому показателю, как способность управлять страной, ФСП уступает только партии «Республиканцы» и имеет одинаковый рейтинг с партией президента «Вперед, Республика!», опережая ЕЕЛВ и две популистские партии. Такой результат вполне ожидаем, поскольку у социалистов большой опыт в руководстве страной. В то же время ФСП не воспринимается населением как главный защитник интересов французов. По этому показателю она опережает лишь партию «Непокоренная Франция», находится примерно на одном уровне с партией Э. Макрона, но уступает ЕЕЛВ, партиям «Республиканцы» И «Национальный фронт». Аналогичная картина наблюдается и в части поддержки французами проектов развития общества, выдвинутых главными партиями страны.

Несмотря на эти неблагоприятные показатели, руководство ФСП не теряет надежды на успешное выступление социалистов на грядущих общенациональных выборах. Учитывая неожиданные повороты в электоральной истории Франции последней четверти века, целиком исключать такую возможность не следует. Но на момент написания статьи вероятность успеха ФСП, как и всего левого лагеря, выглядит весьма призрачной.

Подводя итог вышесказанному, можно сделать следующие выводы. Во-первых, основными направлениями действий ФСП по укреплению политических позиций стали оппозиционность действующей власти, демонстрация левой идентичности партии и стремление социалистов к сплочению левых сил. Во-вторых, главная новация в политической стратегии ФСП - это готовность поступиться партийными интересами во имя единства действий левого лагеря, а в идеологии - включение экологических ценностей в партийную доктрину. В-третьих, ФСП в 2017-2021 гг. сохраняла политическую идентичность правительственной левой партии. Она отказалась от фронтального противостояния с действующей властью и воздержалась от высказываний

\footnotetext{
${ }^{23}$ Le projet : «Il est temps de vivre mieux»... P. 11-12.

${ }^{24}$ Idem. P. 36.

${ }^{25}$ Les Français et Jean-Luc Mélenchon. Sondage ELABE pour BFMTV 18 septembre 2019 [Ressource électronique]. URL: https:// www.elabe.fr/wp-content/uploads/2019/09/elabe_bfmtv_18092019_les-francais-et-jean-luc-melenchon.pdf (date de la demande: 15.06.2021) ; Les Français et Jean-Luc Mélenchon. Sondage ELABE pour BFMTV 12 novembre 2020 [Ressource électronique]. URL: https://www.elabe.fr/wp-content/uploads/2020/11/melenchon.pdf (date de la demande: 15.06.2021).

${ }^{26}$ Fractures françaises - 2016-2021: un climat pré-présidentielle différent? [Ressource électronique].URL: https://www.ipsos.com/ fr-fr/presidentielle-2022/fractures-francaises-2016-2021-un-climat-pre-presidentielle-different (date de la demande: 08.09.2021).
} 
и предложений популистского характера. В-четвертых, ФСП сумела избежать политической изоляции и превращения в микропартию, сохранила сильные позиции на местном уровне, но так и не смогла заметно усилить авторитет на национальном уровне и сохранить лидерство в левом лагере.

\section{Библиографические ссылки}

1. Вершинин АА. Французские социалисты после выборов-2017: новые вызовы для новой партии. В: Клинова МВ, Кудрявцев АК, Рубинский ЮИ, Тимофеев ПП, редакторы. Франция при президенте Эммануле Макроне: в начале пути: сборник статей по итогам II Всероссийской научной конференщии франковедов; 13 октября 2017 г.; Москва, Россия. Москва: ИНИОН РАН; 2018. с. 92-99.

2. Нарочницкая ЕА. Партийно-политический ландшафт Франции после выборов 2017 г. В: Швейцер ВЯ, редактор. Свет и тени «эры Макрона». Москва: ИЕ РАН; 2019. с. 44-55.

\section{References}

1. Vershinin AA. [French socialists after elections-2017: new challenges for a new party]. In: Klinova MV, Kudryavtsev AK, Rubinskii YuI, Timofeev PP, editors. Frantsiya pri prezidente Emmanule Makrone: v nachale puti: sbornik statei po itogam II Vserossiiskoi nauchnoi konferentsii frankovedov; 13 oktyabrya 2017 g.; Moskva, Rossiya [France under president Emmanuel Macron: at the starting point: collection of articles on the results of $2^{\text {nd }}$ All-Russian scientific conference of francoists; 2017 October 13; Moscow, Russia]. Moscow: Institute of Scientific Information for Social Sciences of the Russian Academy of Sciences; 2018. p. 92-99. Russian.

2. Narochnitskaya EA. [Party-political landscape of France after elections-2017]. In: Shveitser VYa, editor. Svet $i$ teni «ery Makrona» [Light and shadows of the «Macron era»]. Moscow: Institute of Europe of the Russian Academy of Sciences; 2019. p. 44-55. Russian. 